\title{
A CONSIDERATION OF NORMAL AND ABNORMAL POSITIONS OF THE HILUM OF THE KIDNEY
}

\author{
JACOB PRIMAN \\ Department of Anatomy, University of Michigan. \\ TWO FIGURES
}

In our study of the literature dealing with the causes of congenitally displaced kidneys we found a peculiar anomaly of the kidney, described by Cords ('11), where the hilum renale had an abnormal position. That anomaly, which will be discussed more fully later, aroused our interest in the occurrence or development of different positions of the hilum renale. The material gathered in the University of Latvia for a consideration of this question is not as yet complete for publication. However, in the Anatomical Museum of the University of Michigan we have had the opportunity of studying a kidney specimen which affords a partial example, at least, of the points which we wish to illustrate. For permission to publish an account of this anomaly we wish to express our cordial gratitude to Prof. G. Carl Huber, the director of the Department of Anatomy of the University of Michigan.

The specimen was found in the body of a young male. There is no information about the other abdominal organs. Judging from the origin and termination of the kidney blood vessels, it is to be assumed that the kidneys were placed at the normal height and in the normal position.

The measurements of the kidneys are as follows: Right kidney: length, $8.5 \mathrm{~cm}$; width, $3.5 \mathrm{~cm}$; thickness, $4.6 \mathrm{~cm}$. Left kidney : length, $9.5 \mathrm{~cm}$.; width, $4.5 \mathrm{~cm}$.; thickness, $3.2 \mathrm{~cm}$. Thus the right kidney is somewhat shorter and narrower, but a little thicker than the left one; the former is the more 
compressed from side to side. The surfaces of both kidneys show superficial lobulation. Each kidney has one artery and one vein. The arteries arise in the normal position from the abdominal aorta and enter the hilum of the kidney (the
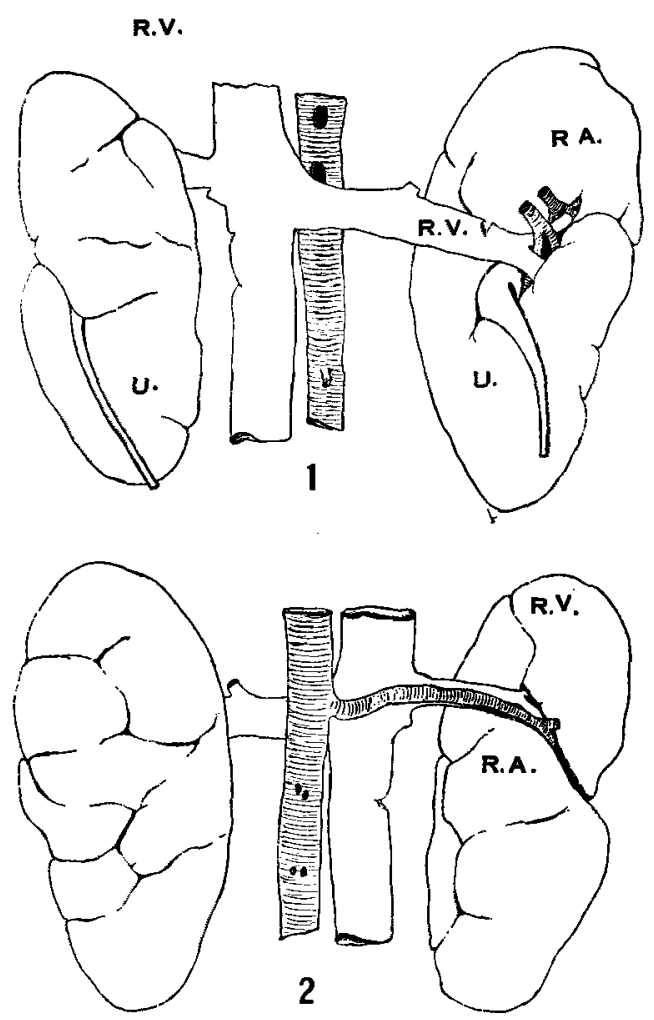

Fig. 1 Human kidney with abnormal position of hilum, ventral view. Onehalf natural size. R.A., renal artery; R.V., renal vein; $V$, ureter.

Fig. 2 Human kidney with abnormal position of hilum, dorsal view. Onehalf natural size. R.A., renal artery; R.F., renal vein.

artery of the left kidney has been cut off). The veins terminate in the inferior vena cava.

Right kidney (figs. 1 and 2). This kidney has an acute superior end and shows larger lobulation on the dorsolateral surface. The hilum renale is situated on the dorsal and lateral surfaces of the organ, chiefly on the former. It has 
the shape of a deep, narrow groove extending from the upper third of the dorsal surface (near to the medial border) downward and lateralward, passing for a short distance on the lateral border of the anterior surface; i.e., the hilum renale is placed dorsolateralward. The pelvis renalis cannot be seen in the figures, it is hidden in the deep groove. The ureter appears on the lateral lower part of the hilum (groove) and runs almost straight downward and forward over the ventral surface of the kidney; it lies, during its course, in a shallow groove, which has the appearance of being a continuation of the hilum. The shape and size of the ureter are normal.

Left kidney (figs. 1 and 2). The organ has the shape of an ellipsoid with the upper end larger; the dorsolateral surface being the most lobulated part of the kidney. The hilum renale, which lies in the middle of the ventral surface of the kidney, is relatively short and not very large; it extends from the upper lateral part of the ventral surface downward and medialward. The upper part of the hilum is occupied by the blood vessels, the lower by the ureter. The pelvis renalis is situated medialward and caudalward from the blood vessels. The ureter passes downward over the ventral surface of the kidney. It has a normal shape and size.

From the foregoing description, it is to be seen that the kidneys differ from the normal in respect to shape, to the presence of some larger lobulation, and particularly with regard to the hilum renale. On the right kidney it is on the dorsolateral surface, while the ureter runs over the ventral surface.

Before we pass to a consideration of the factors underlying the position of the hilum renale in general, we wish to call attention to the article of Cords, already mentioned, and to one case given by Brown ('94). Both of these cases have some resemblance to the anomaly described above. In Cords' case one of the two normally placed kidneys-the right one-has the hilum renale in the usual place, while the left one has the hilum on the ventral surface of the organ; 
otherwise the kidneys are normal. Brown describes in his paper an anomaly where the left kidney has normal structure, a normal position of the hilum renale, and lies in the normal place; while the right one, which has a normal shape and which lies on the bifurcation of the aorta, shows the hilum renale situated on the lateral border of the kidney. Thus in each of these cases there is an abnormal position of the hilum renale of one kidney.

What is the explanation of these different positions of the hilum renale? The embryologists, without exception, state that the normal situation of the hilum (on the medial border of the kidney), which is attained about the second part of the second month (i.e., when the embryo is about 20 to $30 \mathrm{~mm}$. in length), results from the rotation of the organ around its long or vertical axis. This rotation occurs in such a way that the hilum, which at the beginning of development lies on the ventral surface of the kidney, is displaced medialward-the lateral surface of the organ becoming ventral. Huber and Bonnet both state that the "primary renal pelvis" rotates on its axis "in such a way as to make its dorsal surface have a more lateral position." Up to this time, various observers, relying upon this statement, have explained the different positions of the hilum renale only on the basis of this rotation. When the hilum is found on the ventral surface of the kidney, then, it is said, the kidney has either rotated insufficiently or not at all; when on the dorsal surface, it is believed that the organ has rotated too far on its vertical axis. Cords, also, has used this explanation, saying, "dass aus irgend einem uns vorläufig nicht ersichtlichen Grunde die linke Niere verhindert wurde, die ihr zukommende Drehung medianwärts auszuführen." Anyone who will study Cords' figures can easily be convinced that his case cannot be explained by a rotation of the left kidney; rather the anterior ventral lip of the sinus renalis has not developed and the hilum has the appearance of being situated on the ventral surface. The same condition is illustrated by the right kidney, but in much less degree. 
In describing his case Brown states: "the kidney seemed to have undergone a considerable amount of rotation around a vertical axis whereby its posterior surface became practically anterior-the hilum being to the right side and placed somewhat posteriorly; the ureter was normal, although very short." If in this case we were to accept the possibility of a rotation, then we could explain the position of the hilum only by the rotation of the kidney in the opposite direction, i.e., the embryological medial surface must become ventral and the hilum must lie on the lateral border of the kidney. There is no possibility of accepting Brown's explanation, that through a rotation "the posterior surface became practically anterior," because the renal blood vessels, which arise and terminate in the internal iliac artery and internal iliac vein, run straight to the hilum and the ureter is placed dorsally in respect to the blood vessels.

In the case described by us, one might state that the left kidney did not rotate at all around its long axis, while the right kidney rotated too far; i.e., in place of the $90^{\circ}$, it rotated more than $180^{\circ}$, but less than $270^{\circ}$. However, accepting this as a possibility, we are unable to explain the ventral course of the ureter of the right kidney, which should lie on the dorsal surface of the kidney if such a rotation had occurred.

From this short consideration it is to be seen that if we accept as an explanation of the different positions of the hilum renale, the rotation of the kidney around its long axis, then we also must assume, 1) that this rotation can oceur when the kidney does not ascend and, 2) that the organ may rotate in both directions, usually to the medial and, more seldom, to the lateral side. A possible rotation to the lateral side is not mentioned in the present literature. At the same time it must be said that not all facts can be explained by a rotation in either direction; for example, the ventral course of the right ureter in our own case.

But is it not possible to explain the different positions of the hilum renale in other ways than by rotation? We think 
it is. It is a noteworthy fact that, while many embryologists have noted very precisely the time at which the rotation of the kidney or the primary pelvis occurs, none give explanation as to the causes of this rotation; at least we have been unable to find a statement regarding this matter in the literature. We are in doubt as to whether there does occur an actual rotation of the kidney which is associated with the displacement of the hilum.

Just at the time of the rotation, the ureter branches very rapidly, there is not as yet full connection between the secretory and excretory parts of the kidney and a fully differentiated capsule is not present, i.e., the kidney is not fully separated from the surrounding tissue. Felix points out, also, that "all tubules from those of the second order and third order onwards, are so arranged that they run as well in the dorsal as in the ventral direction, two usually running ventrally and one dorsally' ('12, p. 837). In his figures (figs. 580 and 581) it is to be seen that the ventral branches of the primary pelvis are greater in number than those of the dorsal one. On page 841 he writes, "detailed statements as to the branching of the individual collecting tubules will be possible only when numerous models have been prepared, since these alone allow of a certain count."

From this discussion we think it is possible to conclude that the displacement of the hilum renale does not occur through an actual rotation of the kidney around its vertical axis. Rather we must take into account the possibility that the divisions of the primary pelvis branch and grow more easily in the lateral and especially in the ventral direction (more branches in the ventral direction-Felix), because the growth in the dorsal and medial directions is limited by the dorsal body wall. Through such a growth the hilus and the primary pelvis gradually shift their position in the medial direction, toward the medial border of the kidney. When we look at the separate developmental stages, this gradual displacement gives the impression of a rotation, but this appears to be only an illusion. 
In this regard it is interesting to note that not all anatomists have recognized the same position of the hilum renale as normal for normally developed and situated kidneys. The greatest number of them consider the normal position of the hilum renale as one directly on the medial border of the organ. Certain observers (Gegenbauer, Sappey, Quain) regard the medial part of the ventral surface as the normal place, while Hauch states: "Überhaupt fand ich im Gegensatz zu Sappey und Quain den Hilus meistens an der dorsalen Seite der Niere." Other authors mention the fact that the hilum is found not infrequently on the dorsal surface. Thus, from the writings of anatomists it is to be seen that the variations in the normal position of the hilum renale depend chiefly upon the development of the labium anterior of the hilum and that generally it is shorter than the dorsal labium. Series could easily be built up from the material in any anatomical preparation room which would illustrate the gradations in the length of the ventral labium, with cases very like that recorded by Cords as one extreme, and those in which the ventral lip is even longer than the dorsal one as the other extreme. However, by this statement we do not intend to imply that it is possible to determine the greater or less development or branching of the primary renal pelvis by a study of the adult kidney; we know that all primary branches to the fifth order are taken, in later development, into the definite renal pelvis and calyces. Furthermore, in the adult kidney, other factors or changes may have very important effects.

That the hilum can be displaced in the opposite direction, i.e., lateralward, or even in this way on the dorsal surface is shown in the cases described by Brown ('94) and by us. These two cases differ only in this, that in the first case the kidney did not ascend (it remained in the place where, after Hauch, it lies in an 8- to 10-mm. embryo); therefore, the kidney blood vessels are branches of the vasa iliaca interna and go medianward to the kidney; in our case, with the displacement of the right kidney upward and lateralward, the 
blood vessels course over the dorsal surface; and the ureter, for the same reason, passes over the ventral surface of the kidney. The explanation which we have offered makes entirely clear and logical the course of the ureter, while its position on the ventral surface cannot be explained by any rotation of the kidney.

These two cases and all the cases of dystopia renis congenita, with the hilum renale on the ventral surface of the kidney (which is one of the characteristic marks of this type of kidney anomaly) or even on the medial border of the organ, clearly show that the position of the hilum is not always firmly fixed with the ascending of the kidney. As a rule, in the ascending of the kidney the hilum renale is displaced medialward, but in the congenitally displaced or pelvic kidney it retains its embryological position on the ventral surface. The latter condition is to be explained through the hindrance of kidney growth in the normal direction; this prevention of growth is the cause in these cases where the hilum renale is found on the ventral surface of a normally situated kidney. What the underlying cause of this hindrance to growth is we do not know as yet, just as we do not know why the hilum is displaced to the dorsal surface. The entirely dorsal position of the hilum may occur in two ways: through a considerable growth or overgrowth in the medial direction or, what must be more rare, by such an overgrowth in the lateral direction. Finally, we think it probable that certain of the abnormal positions of the hilum renale are due to abnormal outgrowths from the primary ureter or may develop through abnormal ingrow1hs of this tube into the nephrogenetic tissue.

From this consideration it is possible to conclude that:

1. The normal position of the hilum renale does not develop by the actual rotation of the kidney around its long axis, but by the more considerable regional growth of the organ in the lateroventral direction. 
2. By reason of as yet unknown forces, growth can occur in the opposite direction, i.e., to the lateral side.

3. By reason of an overgrowth laterally or medially, there can develop a dorsal position of the hilum renale.

\section{BIBLIOGRAPIIY}

BoNNET, R. 1907 J shrbuch der Entwicklungsgeschichte. Berlin.

Broman, J. 1911 Normale und abnormale Entwicklung des Mensehen.

Brown, McDonalis 1894 Variations in the position and derelopment of the kidneys. Jour. of Anat. and Pliys., vol. 28.

Conds, E. 1911 Ueber eine Anomalic des Nierenbeckens bei normaler Lage des Organes. Anat. Anz., Bd. 38.

F'ELIx, W. 1912 Manual of human embryology, vol. 2.

Gegenbauer, C. 1892 Lehrbuch der Anatomie des Menschen, Bd. 2.

$\mathrm{H}_{\mathrm{AUCH}}$ E. 1903 Über die Anatomie und Entwieklung der Nieren. Anat. Hefte, Bd. 22.

HIEnl,e, J. 1873 Anatomie des Menschen, Bd. 2.

Huber, G. CARL 1905 Development and shape of the uriniferons tubules. Am. Jour. Anat., vol. 4, Supplement.

Küster, E. 1895 Deutsche Chirurgie, Lief. 526, H. 1.

PRIMAN, J. 1924 Dystopia renis congenita als atawistische Erschejnung. Acta Univ. Latviensis, Riga.

QUAIN, R. 1896 Elements of anatomy, vol. 3.

SAPPEY, C. 1889 Traité I'anatomie descriptive, vol. 4. Paris. 